\title{
RANCANG BANGUN PENAMPIL INFORMASI KEBUN BINATANG BERBASIS KOMPUTER PERSONAL MINI
}

\author{
Denny Darlis ${ }^{1}$, Gina Ilma Amalia ${ }^{2}$ \\ D3 Teknik Telekomunikasi, Universitas Telkom \\ Jl. Telekomunikasi Terusan Buah Batu, Bandung \\ ${ }^{1}$ denny.darlis@tass.telkomuniversity.ac.id \\ ${ }^{2}$ ginailmaamalia@gmail.com
}

\begin{abstract}
Conventional information systems that are installed and used in public service places such as city parks require expensive and complex systems. To streamline cost and installation time, system complexity can be simplified using a relatively inexpensive system while still providing sufficient service to the community. In this study the display boards of information prepared for zoo services managed by the city government, designed and built using a mini personal computer that is now widely available on the market. To perform its function as an information display board, some eye-catching animated videos are played back and forth as needed. From the results of the implementation and testing in actual conditions it is concluded that the information display system at the zoo using personal mini computer is more interesting for visitors with a delay time of 10.82 seconds for 8 hours of playback. This indicates that this system can work reliably enough to provide information according to the visitor's needs without interruption of time delay between video information.
\end{abstract}

Keywords - Mini PC, Information Display System, Public Zoo.

\section{Pendahuluan}

Suatu objek wisata kebun binatang memiliki keterbatasan pada penyampaian informasi juga mengalami hambatan dalam mengadopsi TIK (Teknologi Informasi dan Komunikasi) sebagai sarana utama aktivitasnya. Untuk itu, diperlukan perencanaan yang matang, implementasi yang cermat, serta pemilihan teknologi yang tepat sesuai dengan kebutuhan dan biaya yang proporsional. Penerapan dan pemanfaatan TIK harus mendorong percepatan dan peningkatan kinerja, menjadi solusi yang efektif dan efisien, bukan menjadi masalah baru. Sumber daya manusia dan manajemen merupakan aset penting dalam strategi penerapan dan pemanfaatan TIK .

Pada kenyataannya suatu media informasi tersebut banyak yang bersifat kurang menarik, karena hanya mengandalkan papan informasi sebagai media aksesnya. Keadaan tersebut membuat informasi kurang efektif untuk tersampaikan ke setiap orang. Serta dalam kenyataan di beberapa tempat kurang mendukungnya fasilitas yang ada untuk membantu menginformasikan mengenai denah objek wisata serta informasi flora dan fauna, yang terdapat di kebun binatang.

Pada penelitian sebelumnya oleh Wildan Ihsan Nuriman [1] telah dibuat media center yang sama namun berbeda penerapannya pada sebuah kendaraan umum, media center yang ditampilkan memiliki delay booting 16.1 detik sampai dengan menjalankan video, dan video yang ditampilkan sebanyak 10 buah,

juga waktu pada log file hasil pemutaran video tidak menunjukan waktu yang real time, karna perangkat raspberry-pi tidak selalu terhubung dengan internet Oleh karena itu pada penelitian kali ini dirancanglah suatu sistem pendukung yang bersifat interaktif dan komunikatif agar dapat lebih menarik minat masyarakat dengan memberikan informasi mengenai denah objek wisata kebun binatang, serta berbagai macam informasi mengenai flora dan fauna yang yang ada di kebun binatang dengan delay yang lebih sedikit juga $\log$ file pemutaran video nya 
menunjukan waktu yang benar tanpa harus terus terhubung dengan internet.

\section{TINJAUAN PUSTAKA}

\section{A. Sistem Informasi}

Sistem informasi adalah alat untuk menyajikan informasi sedemikian rupa sehingga bermanfaat bagi penerimanya. Tujuannya adalah untuk memberikan informasi dalam perencanaan, memulai, pengorganisasian, operasional sebuah perusahaan yang melayani sinergi organisasi dalam proses mengendalikan pengambilan keputusan (Kertahadi,2007).

\section{B. Komputer Personal Mini}

Komputer personal mini merupakan sebuah piranti digital yang merupakan sistem mikroprosesor terintegrasi seperti halnya komputer personal biasa namun memiliki ukuran yang jauh lebih kecil karena dirancang dan diimplementasikan dengan ukuran mini namun memiliki kemampuan standar komputer pada umumnya namun dengan sumber daya terbatas. Komputer personal mini menggunakan Systemon-Chip yang menggabungkan fungsi mikroprosesor dan unit pemroses grafik secara berbagi. Port yang disediakan umumnya berupa port USB, port grafis analog dan digital, port suara analog, dan port GPIO.

\section{Sistem Operasi}

Sistem operasi adalah seperangkat program yang mengelola sumber daya perangkat keras komputer atau hardware, dan menyediakan layanan umum untuk aplikasi perangkat lunak.

\section{TV LCD}

LCD adalah Liquid Crystal Display adalah suatu jenis media tampilan yang menggunakan kristal cair sebagai penampil utama.

\section{E. HDMI}

HDMI (High-Definition Multimedia Interface) adalah standar antarmuka (interface) yang digunakan pada berbagai perangkat audiovisual seperti televisi definisi tinggi (high definition) dan home theater.

\section{F. Kartu Memori}

Kartu memori merupakan sebuah alat (card) yang berfungsi sebagai tempat penyimpanan data digital (seperti gambar, audio dan video) pada sebuah gadget seperti kamera digital, PDA dan Handphone.

\section{G. Video}

Video adalah teknologi pemrosesan sinyal elektronik mewakilkan gambar bergerak. Aplikasi umum dari teknologi video adalah televisi, tetapi dia dapat juga digunakan dalam aplikasi teknik, keilmuwan, produksi dan keamanan.

\section{H. Animasi}

Animasi merupakan suatu teknik menampilkan gambar berurut sedemikian rupa sehingga penonton merasakan adanya ilusi gerakan (motion) pada gambar yang ditampilkan.

\section{Perancangan Sistem}

\section{A. Spesifikasi Sistem}

Desain perancangan adalah hal utama yang harus dilakukan untuk menunjang merealisasikan alat. Langkah awal dalam pembuatan sistem pusat informasi kebun binatang ini membutuhkan suatu perancangan terhadap segala hardware maupun software yang diperlukan sehingga dengan adanya perencanaan tersebut diharapkan hasil perancangan alat ini dapat direalisasikan dengan baik.

Tujuan dari pembuatan sistem pusat informasi denah ini adalah memperluas alur komunikasi, serta membantu pengunjung / pengguna objek wisata untuk mendapatkan berbagai informasi hewan/fauna melalui sebuah tampilan media center, sehingga informasi yang disampaikan menjadi efektif dan lebih menarik .

\section{B. Mekanisme kerja sistem}

Berdasarkan studi literatur yang
dilakukan penulis, maka telah dilakukan
pembuatan media center yang berisi berbagai
macam informasi di kebun binatang.




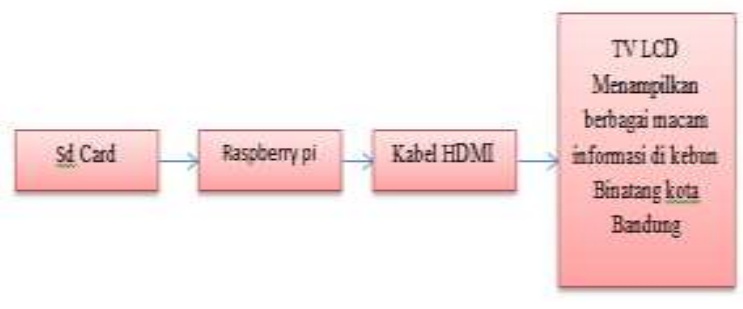

Gambar 1. Blok diagram sistem

Proses dimulai dimana instalasi os raspbian yang dilakukan di sd card yang nantinya dipasang pada raspberry pi. Setelah itu raspberry pi disambungkan ke tv lcd dengan menggunakan kabel hdmi dan tv lcd menampilkan konten yang berisi berbagai macam informasi pada Kebun binatang yang telah dibuat.

\section{E. Diagram alir Pembuatan Sistem}

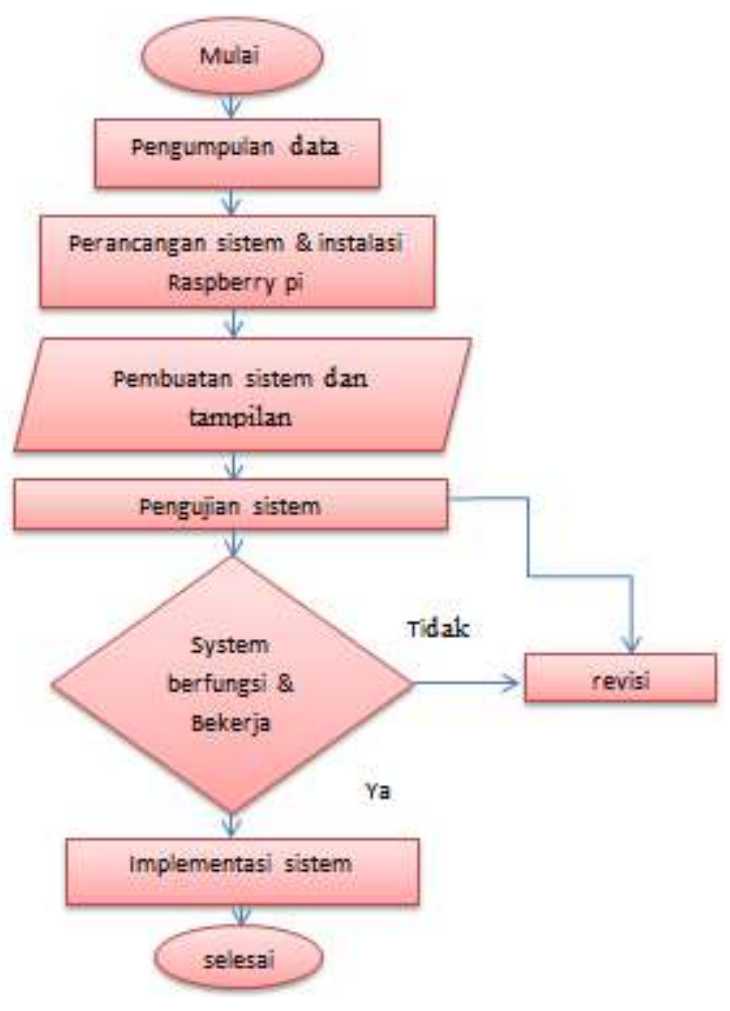

Gambar 2 Diagram alir pembuatan

Gambar 2 merupakan flowchart pengerjaan dari perancangan media center ini. Langkah pertama yaitu pengumpulan data berbagai macam informasi kebun binatang untuk bahan pembuatan konten pada media center, selanjutnya membuat perancangan dan instalasi raspberry pi, kemudian penginputan data untuk isi konten, setelah itu tahap pengujian jika berhasil maka akan langsung pengimplementasian alat di tempat yang akan dipasang media center di kebun binatang kota $S$

Sedangkan jika tidak maka kembali lagi untuk perancangan sistem dan instalasi raspberry pi, setelah berhasil dan diimplementasikan maka selesailah perancancangan dari media center ini.

\section{Pemilihan Perangkat}

\section{C.1 Piranti Keras}

a. Raspberry-pi model $2^{[2]}$

Raspberry Pi B model 2 Prosesor 900MHz quad-core ARM Cortex-A7 CPU, 1GB RAM

\section{b. Memory Card ${ }^{[1]}$}

Pada penelitian kali ini digunakan memory card dengan kapasitas 16 gb dengan fungsi untuk instalasi OS juga media penyimpanan video.

$$
\text { c. } \operatorname{HDMI}^{[1]}
$$

Pada penelitian kali ini digunakan kabel HDMI to HDMI.

$$
\text { d. TV } \operatorname{LCD}^{[1]}
$$

Tv lcd yang digunakan yaitu dengan ukuran 42 inch.

\section{f. Adaptor DC 5 Volt $^{[2]}$}

Power yang diperlukan oleh Raspberry $\mathrm{Pi}$ berasal dari adaptor, tegangan yang dibutuhkan oleh adalah $5 \mathrm{~V}$ dengan arus 1,2 A.

\section{g.Heatsink}

Heatsink berfungsi untuk membantu proses pendinginan pada sebuah prosesor.

\section{C.2 Software}

a.Raspbian Wheezy ${ }^{[1]}$ 
Raspbian adalah sistem operasi bebas berbasis Debian GNU / Linux yang dikeluarkan yayasan Raspberry $\mathrm{Pi}$ dengan pengaturan kompilasi disesuaikan untuk menghasilkan kode yang akan berjalan pada Raspberry Pi.

\section{b.OMXPlayer ${ }^{[2]}$}

OMXPlayer adalah sebuah media yang digunakan untuk pemutar video khusus dibuat untuk GPU Raspberry Pi yang dibuat oleh Edgar (Gimli) Hucek dari proyek XBMC digunakan pada operating sistem linux debian. Format video yang Dapat diputar oleh omxplayer adalah .Mp4

$$
\text { c.WinSCP }{ }^{[2]}
$$

WinSCP (Windows Secure CoPy) adalah aplikasi open source client SFTP, SCP ataupun FTP di windows. Fungsi utamanya adalah menyediakan sarana pengiriman data yang aman antara komputer lokal dan komputer remote atau dengan kata lain saling bertukar data antara komputer klien dengan komputer remote (server).

$$
\text { d.ExtraPutty }{ }^{[1]}
$$

Putty adalah aplikasi pengganti remote login seperti telnet, rsh, dan rlogin, yang jauh lebih aman. Fungsi utama aplikasi ini adalah untuk mengakses mesin secara remote Dengan SSH, semua percakapan antara server dan client di enkripsi.

$$
\text { e.X-ming }{ }^{[1]}
$$

Xming menjalankan aplikasi linux tanpa prantara virtual machine. Xming sebenarnya diperuntukan untuk mengendalikan secara remote komputer linux dengang koneksi SSH, namun ini juga bisa dimanfaatkan untuk menjalankan aplikasi windows dan linux side-by-side.

\section{f. Wideo}

Merupakan aplikasi untuk membuat video animasi berdasarkan pada web dapat memilih objek yang akan digunakan pada halaman , kemudian penambahan animasinya sesuai dengan yang apa yang inginkan.

$$
\text { g. Vegas Pro } 11.0
$$

Sony vegas pro 11.0.700 ini adalah salah satu software edit video yang dilengkapi dengan banyak animasi yang akan membuat video yang kita edit menjadi lebih bagus dan dengan kualitas HD ( High Definition ).

\section{h.Camstudio}

Camstudio merupakan aplikasi di PC yang berguna untuk merekam kegiatan yang ada di tampilan PC. Aplikasi ini serupa dengan snapshot namun berbeda hasilnya.

Implementasi dan hasil pengujian

\section{A. Implementasi Sistem Pusat Informasi Kebun Binatang}

A.1 Implementasi Perangkat Keras

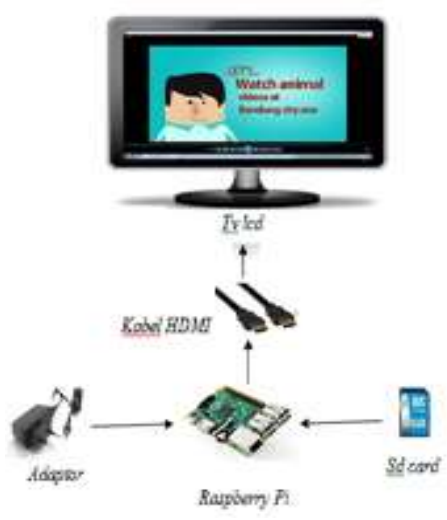

Gambar 3. Sistem tampilan informasi kebun binatang

Berdasarkan blok diagram diatas, sistem memiliki spesifikasi sebagai berikut :

1.Sumber tegangan berasal dari listrik yang disalurkan oleh adaptor ke raspberry pi.

2. SD card digunakan untuk media penyimpanan sistem operasi dan konten berupa video sebagai pendukung sistem yang dibuat .

3.Untuk menampilkan keluaran dari sistem , maka digunakan monitor dengan penghubung kabel HDMI.

4. Raspberry pi sebagai sistem.

\section{A.2 Implementasi Piranti Lunak}




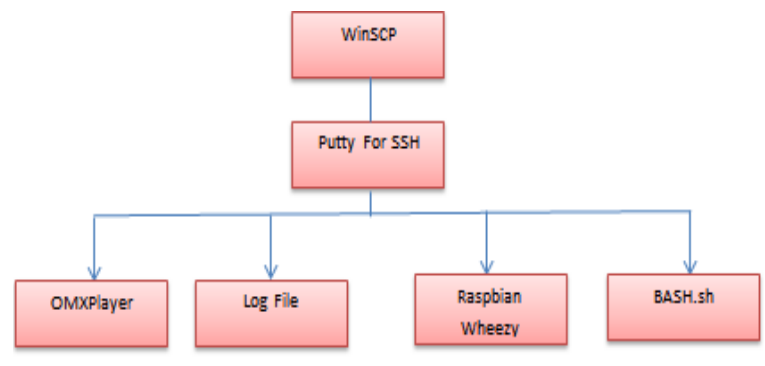

Gambar 4. Implementasi sistem perangkat lunak

1. Operating sistem yang dipakai pada pembuatan sistem ini adalah Raspbian wheezy yaitu suatu sistem operasi berbasis linux debian yang digunakan untuk mini pc Raspberry pi.

2. OMXPLAYER berfungsi sebagai media pemutar suatu video dimana pada penelitian yang dibuat penulis fungsinya adalah memutarkan video ataupun gambar yang berisi berbagai informasi yang berada di kebun binatang pada raspberry pi.

3. Bash.sh adalah suatu bahasa shell script berbasis linux yang dimana pada penelitian ini digunakan untuk membuat script autostart looping video, membuat Logfile.

4. Putty adalah suatu software remote console/ terminal pada laptop yang bertindak sebagai klien yang digunakan untuk menerima data,mengirim data, dan meremote raspberry dengan terhubungnya menggunakan port SSH atau sebagainya.

5. WinSCP adalah aplikasi yg berfungsi untuk transfer file atau copy file antara windows dengan linux.WinSCP digunakan sebagai alat untuk transfer, atau upload dan download file melalui protokol ftp dan secure shell (SSH), Dengan WinSCP kita dapat melakukan editorial seperti mengedit isi file, merubah nama file menghapus file dan lain sebagainya.

\section{A.3 Proses instalasi sistem}

\section{Installasi Raspbian whezzy}

sediakan sd card yang kosong masukan sd card ke adapter dan masukan pada pc atau laptop install raspbian menggunakan win 32 diskimager, kemudian pada menu "Image File" masukan folder dimana OS yang akan kita gunakan, pada menu "device" pilih device yang akan kita gunakan untuk membuat OS. Setelah semuanya selesai lalu Write tunggu beberapa saat sampai proses selesai.

\section{Setting ip pada Raspberry Pi}

Mengganti ip raspberry pi agar mempermudah mengakses dan untuk menyesuaikan ip. Buka terminal raspberry lalu masukan perintah berikut :

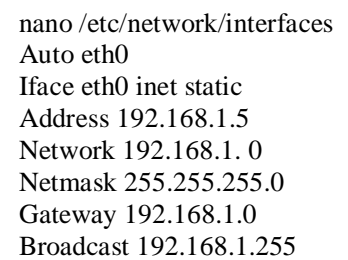

Setelah mengganti ip lakukan restart interface dengan cara mengetikan sudo reboot pada terminal raspberry

3. Upgrade dan Upgrade Raspberry Pi Setelah itu lakukan update dan upgrade raspberry untuk memperbaharui system dan aplikasi.

Update dan upgrade Update : Sudo apt-get update

Upgrade: apt-get upgrade

\section{Installasi OMXplayer}

Langkah selanjutnya yaitu installasi OMXplayer, masukan perintah berikut:

sudo apt-get install omxplayer

5.Installasi fbi

Langkah selanjutnya yaitu instalasi fbi, masukan perintah berikut:

sudo apt-get install fbi

6.Installasi python-symbus dan i2c-tools

Langkah selanjutnya yaitu instalasi python-symbus dan i2c-tools, masukan perintah berikut: 
sudo apt-get install -y python-smbus i2c-tools

\section{B. Realisasi Sistem}

\section{B.1 Pembuatan Konten Video}

Pada proses pembuatan konten video animasi yang akan dibuat penulis menggunakan aplikasi wideo.

\section{B.2 Pengubahan format video dan penambahan suara pada video}

Untuk penambahan suara pada video tersebut bisa dilakukan dengan cara klik file lalu open dan pilih suara yang akan digunakan lalu drag file musik tersebut ke track music.

Untuk penyimpanan video format yang digunakan adalah mp4 dikarenakan Format video yang Dapat diputar oleh omxplayer adalah .Mp4 pilih render as pilih format video yang akan digunakan lalu klik ok .

\section{B.3 Pembuatan Autologin, Autoshutdown dan Autostart}

1. Autologin

Autologin berfungsi untuk mempermudah pengguna system tanpa harus melakukan login, jika menyalakan raspberry pi maka system akan secara otomatis masuk ke tampilan desktop raspberry pi, caranya buka terminal raspberry pi ketikan perintah

sudo nano /etc/inittab

Geser script sampai dengan baris

1:2345:respawn:/sbin/getty -noclear 38400

tty1

Ubah script menjadi

\#1:2345:respawn:/sbin/getty -noclear 38400 tty 1

Dibawah line tersebut kita tambahkan dengan script 1:2345:respawn:/bin/login -f pi tty $1</$ dev/tty $1>/$ dev/tty1 2>\&1

CTRL $+\mathrm{X}, \mathrm{Y}$

2. Autoshutdown
Berfungsi untuk mematikan atau memberhentikan sistem dalam waktu yang ditentukan.

sudo su -

crontab -e

$1516 * * * /$ sbin/shutdown $-\mathrm{r}+1$

Maka sistem akan berhenti pada pukul 16.15

3. Autostart

Berfungsi sebagai media pembuka otomatis. Buka terminal raspberry lalu ketikan

sudo nano /etc/rc.local

. /home/pi/video/loop.sh

B.4 Tahap Upload Konten atau Pembaharuan Video yang akan Diputar kedalam Raspberry $\mathbf{P i}^{[2]}$

Buka software WinSCP dan masukan ip static raspberry di kolom host name pada kolom user name diisi dengan pi dan pada kolom password diisi dengan raspberry, klik login tunggu beberapa saat Masukan password "raspberry" drag video dari pc kedalam directory Raspberry pi dan tunggu hingga proses selesai.

B.5 Membuat Autostart Looping Video dan Logfile Beserta Waktu/Tanggal Pada Awal Booting ${ }^{[2]}$

Buat sebuah folder baru dimana didalamnya terdapat video atau animasi yang telah kita siapkan untuk diputar misal "loop.sh" dengan cara ketikan cd video lalu ketik sudo nano loop.sh, masukan script looping video pada direktori loop.sh Eksekusi script dengan mengetikan sudo chmod $+x$ loop.sh lalu enter dan ketikan ./loop.sh

\section{B.6 Membuat Splashscreen Pada Saat Awal Booting $^{[2]}$}

Ketik sudo nano /etc/init.d/asplashscreen masukan script splashscreen CTRL $+\mathrm{X}$ untuk menyimpan script tersebut.

Untuk mengeksekusi script tersebut gunakan script : sudo chmod $\mathrm{a}+\mathrm{x}$ /etc/init.d/asplashscreen

sudo insserv /etc/init.d/asplashscreen 
sudo nano /boot/cmdline.txt

tambahkan quiet logo.nologo pada akhir script tersebut lalu ubah console=tty1 menjadi console=tty3

reboot raspberry pi.

\section{B.7 Menambahkan Module RTC (Real Time Clock) ds1307 pada Raspberry pi ${ }^{[4]}$}

raspberry pi :

Konfigurasi Interface $12 \mathrm{C}$ pada

ketikan sudo raspi-config

pilih 8 Advanced Options, lalu pilih A7 12C lalu pilih YES. pilih Finish dan reebot raspberry pi.

sudo nano/etc/modules lalu tambahkan perintah

i2c-bcm2708 dan i2c-dev pada direktori tersebut.

Konfigurasi modul RTC ds1307 :

sudo nano /etc/modules

Lalu tambahkan rtc-ds 1307

CTRL+X ,Y lalu enter setelah itu reebot raspberry pi

Konfigurasi pin RTC pada Raspberry pi :

Pastikan setiap pin terhubung dengan benar agar bisa dikonfigurasikan.lalu ketik sudo i2cdetect -y setelah itu ketik :

sudo nano /etc/rc.local lalu pada directory rc.local tambahkan: echo ds1307 0x68 > /sys/class/i2c-adapter/i2c-1/new_device

hwclock $-\mathrm{s}$ pi

CTRLX, lalu Y setelah itu reebot Raspberry

sudo date -s "28 MAR 2016 13:00:00" dan sesuaikan dengan waktu yang benar.

sudo hwclock dan -w sudo hwclock $-\mathrm{r}$ lalu reebot Raspberry pi.

\section{Pengujian Fungsionalitas}

Pengujian ini dilakukan untuk mengetahui semua fitur yang terdapat pada sistem media center apakah berjalan dengan baik sesuai dengan fungsinya. Pengujian dilakukan dengan cara menggunakan semua fitur yang ada di sistem media center ini apakah berjalan dengan baik tanpa terjadi kesalahan, jika terjadi kesalahan pada saat menggunakan fitur sistem informasi ini maka dilakukan pembenaran pada bagian yang kesalahan sehingga semua fitur yang ada pada sistem informasi yang dibuat bisa berjalan tanpa terjadi kesalahan.

Adapun pengujian yang dilakukan meliputi Autologin dan Autostart looping video pada saat awal booting, dan pengujian transfer data dari software WinSCP kedalam raspberry.

\section{C.1 Pengujian waktu delay sistem}

Pengujian ini sangat penting karena keluarannya akan terlihat secara kasat mata. Pada pengujian ini terlihat jika sistem berjalan baik atau tidak. Parameter pengujian kali ini diantaranya:

1. Delay dari booting sistem

Pengujian ini dilakukan karena mengingat adanya waktu tunggu yang dibutuhkan sistem untuk melakukan autologin

Tabel I menunjukkan timeline video yang akan di putar pada media center.

Tabel I - Daftar video yang akan diputar

\begin{tabular}{|c|c|c|c|c|c|c|c|c|c|c|}
\hline Nama video & 1 & 2 & 3 & 10 & 11 & 12 & 13 & 14 & 15 & 16 \\
\hline Darasi Video (s) & 358 & 313 & $30 \mathrm{~s}$ & $31 \%$ & $35 s$ & $34 s$ & $30 \mathrm{~s}$ & $35 s$ & $31 \mathrm{~s}$ & 558 \\
\hline Nama video & 17 & 18 & 19 & 20 & 21 & 22 & 23 & 24 & 25 & 26 \\
\hline Darasi Video (s) & 298 & $24 s$ & $32 s$ & $34 s$ & 345 & $30 \mathrm{~s}$ & $14 \mathrm{~s}$ & $31 s$ & $37 \mathrm{~s}$ & $33 \mathrm{~s}$ \\
\hline Nama vídeo & 27 & 28 & 29 & 30 & 31 & 32 & 33 & 34 & 35 & 36 \\
\hline Durasi Video (s) & $50 s$ & $37 / 3$ & 33 & $15 s$ & $30 s$ & $29 s$ & $32 s$ & $30 \mathrm{~s}$ & 319 & 13, \\
\hline Nama vídeo & 37 & 38 & 39 & & & & & & & \\
\hline Duras! Video (s) & $3 t s$ & $12 s$ & $37 \mathrm{~s}$ & & & & & & & \\
\hline
\end{tabular}

Bisa terlihat pada skenario pengujian ini terdapat 39 video yang dimasukan kedalam Raspberry.video yang ditampilkan berupa video informasi mengenai hewan atau fauna di kebun binatang, juga video asli dari beberapa hewan yang ada dikebun binatang, juga informasi mengenai fasilitas yang ada di kebun binatang itu sendiri. 
Berdasarkan pengujian yang telah dilakukan maka video pertama akan diputar kembali pada 2 detik 05 mili detik.

Tabel II dan III menunjukkan hasil pengujian perhitungan delay sistem.

Tabel II Hasil pengujian delay sistem ketika di restart dengan jeda waktu 1 menit

\begin{tabular}{|l|l|l|l|l|l|}
\hline Pengujian ke- & 1 & 2 & 3 & 4 & 5 \\
\hline Waktu tunggu (s) & 10.3 & 10 & 10 & 10.3 & 10.8 \\
\hline
\end{tabular}

Pada skenario pengujian delay booting pertama, Raspberry Pi di restart dengan jeda waktu 1 menit mati, maka rata- rata waktu delay adalah 10.28 detik.

Tabel III Hasil pengujian delay sistem ketika di restart dengan jeda waktu 5 menit

\begin{tabular}{|l|l|l|l|l|l|}
\hline Pengujian ke- & 1 & 2 & 3 & 4 & 5 \\
\hline Waktu tunggu (s) & 11.2 & 10.8 & 10.5 & 11 & 10.6 \\
\hline
\end{tabular}

Pada skenario pengujian delay booting kedua, Raspberry pi Pi di restart dengan jeda waktu 5 menit mati, maka rata- rata waktu delay adalah 10.82 detik.

\section{C.2 Pengujian waktu tunggu proses booting terhadap video dengan splashscreen}

Pengujian waktu tunggu proses booting terhadap splashscreen dilakukan untuk mengetahui seberapa lama waktu tunggu raspberry pada saat awal booting sampai dengan memulai autologin dan autostart looping video pada saat pertama dinyalakan.

\section{KEBUN BINATANG KOTA BANDUNG}

Gambar 5. Splashscreen awal tampilan

\section{C.3 Pengujian Pemutaran Video}

Pengujian dilakukan dengan cara menampilkan tampilan awal sistem yang telah dibuat. Pengujian pemutaran video ini diimplementasikan di kebun binatang video berhasil terputar dengan baik sesuai timeline pada raspberry pi selama 9 jam nonstop tanpa berhenti, pengujian dikatakan berhasil apabila dapat melakukan pemutaran seluruh konten video yang ada pada raspberry pi secara otomatis juga dapat menampilkan splashscreen pada saat pergantian video selain itu menampilkan laporan hasil dari pemutaran video di akhir setelah pemutaran video selesai.

\section{C.4 Pengujian Logfile Pemutaran Video}

Pengujian logfile pemutaran video dilakukan untuk mengetahui laporan hasil pemutaran video yang berhasil diputar pada raspberry pi yang dibuat dalam bentuk .txt

Pada pengujian ini video yang sesuai dengan durasinya masing-masing berhasil dicatat lengkap pada logfile berdasarkan parameter yang sudah ditentukan yaitu tanggal, waktu, media yang memutarkan, tempat video disimpan, dan nama video yang telah berhasil diputar pada raspberry.

\section{C.5 Pengujian Subyektif}

Pengujian ini dilakukan untuk mengetahui apakah sistem media center yang telah dibuat sesuai dengan yang diharapkan atau tidak. Pertanyaan yang ada di kuisioner tersebut mencakup fungsional sistem informasi dan tampilan dari media center. Kuisioner diberikan kepada selaku pengurus kebun binatang dan pengunjung kebun binatang yang melihat media center tersebut.

Isi kuisioner lebih terpaku kepada kualitas sistem "'Apakah sistem media center ini bersifat interaktif dan dapat Memberikan informasi mengenai flora dan fauna di kebun binatang juga lebih menarik minat para pengunjung?"

Berdasakan hasil survey yang dilakukan oleh penulis maka hasil yang didapatkan yaitu : 


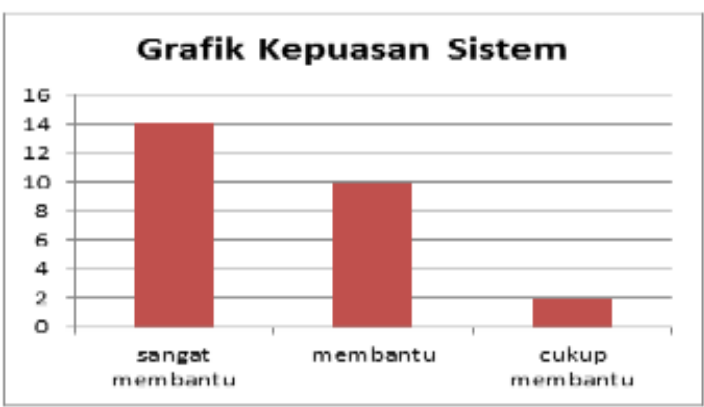

Gambar 6. Diagram Kepuasan Pengguna Sistem

\section{KESIMPULAN}

Berdasarkan proses implementasi, pengujian, dan analisis dapat ditarik kesimpulan sebagai berikut:

1. Sistem Media Center Ini berjalan dengan baik berdasarkan parameter yang dibuat sebelumnya, yaitu dapat otomatis memutarkan video sesuai timeline pada awal pertama raspberry pi dinyalakan tanpa harus login terlebih dahulu beserta mencatat laporan pemutaran yang disimpan pada logfile yang menunjukan waktu yang benar tanpa harus terhubung ke internet, serta menggunakan splashscreen untuk menunggu proses booting.

2. Ketahanan raspberry menjalankan sistem media center ini dapat memutarkan video selama 8 jam nonstop tanpa berhenti dan media center akan berhenti secara otomatis paka pukul 16.15 sesuai ditutupnya kebun binatang .

3. Auto login yang digunakan dapat membantu petugas untuk menyalakan produk.

4. Autostart dapat membantu meringankan kinerja rapberry pi.
Konten video yang ada pada media center cukup interaktif dan bisa membantu memberikan informasi mengenai fauna yang ada di kebun binatang .

\section{UCAPAN TERIMA KASIH}

Terima kasih yang sebesar-besarnya kami ucapkan kepada Program Studi DIII Teknik Telekomunikasi, Universitas Telkom, dan pihak pengelola Kebun Binatang Kota Bandung yang telah memfasilitasi terlaksananya penelitian ini.

\section{DAFTAR PUSTAKa}

[1] G. I. Amalia, D. Darlis, T. A. Riza, Perancangan dan Implementasi Pusat Informasi Kebun Binatang Kota Bandung Berbasis Raspberry-Pi, Proyek Akhir D3, Universitas Telkom, 2016.

A. P. Ramadhan, D. Darlis, I.D. Irawati. Perancangan Dan Implementasi Pusat Informasi Denah Perumahan Perkluster Dibuah Batu Regensi. Proyek Akhir D3, Universitas Telkom, 2014.

W.I. Nuriman, D. Darlis, D. A. Nurmantris, Implementasi Sistem Informasi Kuliner pada Angkutan Publik berbasis $S B C$. Jurnal INFORMATIKA. Politeknik Harapan Bangsa, Tegal, 2017

Tim Dinas Pariwisata dan Kebudayaan Provinsi Jawa Barat. "Dinas pariwisata dan kebudayaan provinsi Jawa Barat" http://www.disparbud.jabarprov.go.id/wisata/destdet.php?id=486\&lang=id (diakses pada tanggal 5 November 2015)

D. Darlis, R. Tulloh, S.K. Saleh. Sistem Media Center Periklanan Pameran Di Bandung Berbasis Raspberry $P i$ Mengunakan Serviio". Jurnal Elektro dan Telekomunikasi Terapan, Vol 3 No. 2, Universitas Telkom, 2016

Hawkins, Matt. "Adding a DS3231 Real Time Clock To The Raspberry Pi” http:// www.raspberrypispy.co.uk/2015/05/adding-a-ds3231-real-time-clockto-the-raspberry-pi/ (diakses pada tanggal 28 Maret 2016)

Hawkins, Matt. "Enabling The I2C Interface On The Raspberry Pi” http://www.raspberrypispy.co.uk/2014/11/enabling-the-i2c-interface-on-theraspberry-pi/ (diakses pada tanggal 28 Maret 2016) 
Rancang Bangun Penampil Informasi Kebun Binatang Berbasis Komputer Personal Mini 